\title{
TOWARDS A PEDAGOGICAL MODEL FOR TEACHING THROUGH RATHER THAN MERELY WITH TECHNOLOGY: A CULTURAL HISTORICAL APPROACH
}

\author{
J. Hardman \\ School of Education \\ University of Cape Town \\ Cape Town, South Africa \\ http://orcid.org/0000-0002-1592-7357
}

\section{ABSTRACT}

The global impact of COVID-19, a pandemic that has seen much of the world resort to stringent lockdown rules and the closing of schools, poses challenges for teaching/learning as what was originally a face to face endeavour, has now become an online activity. I have argued in a national newspaper for the distinction between teaching with technology and teaching through technology. In this exploratory article, I engage with this distinction and move towards developing a model of online pedagogy that can lead to learning, in the absence of face to face engagement. The article argues for a pedagogical model capable of delivering content in the absence of a face to face teacher and illustrates this through data from an online intervention with my Honours students. The case study described is exploratory in nature and seeks to understand how an intervention can be set up to effect acquisition, rather than seeking to provide evidence for the success of such an intervention. I draw on the work of Vygotsky (1978) and Hedegaard (1998) to provide a picture of developmental pedagogy that leads to cognitive development. The article argues for how it is possible for online pedagogy to achieve developmental learning by providing findings that indicate how one can teach through technology.

Keywords: teaching through technology, higher education, cultural historical theory, teaching for learning.

\section{INTRODUCTION}

The impact of COVID-19, an infectious and deadly virus, has led to the shut down of many economies across the world. The picture is no different in South Africa where extreme lockdown measures have been implemented for the past 2 months. All schools are closed, and most businesses and non-essential shops are effectively shut down. This has led to an increase in online teaching and learning in a bid to rescue the schooling year. In a recent op-ed in national newspaper (Hardman 2020) I argued that while teaching with technology is possible, teaching through technology is not. My argument hinges on the fact that teaching and learning are developmental; teaching requires that children acquire concepts, not simply facts, and 
conceptual development is extremely difficult to achieve by teaching through rather than with technology. This is especially so for younger grades who are developmentally unable to grasp concepts in the absence of concrete examples of the concepts (Piaget 1976). Moreover, there is a significant body of research indicating that technology cannot develop a child cognitively, rather, positive benefits of technology require a very specific kind of pedagogy, generally referred to as constructivist pedagogy (Fisher, Lucas, and Galstyan 2013; Tay 2016; Tamim et al. 2011; Rosen and Salomon 2007; Geer et al. 2017; Falloon and Koo 2014; Roschelle et al. 2010; Mercer, Dawes and Staarman 2009; Zurita and Nussbaum 2004). Based loosely on the work of Piaget (1976) and Vygotsky (1978) this approach appreciates that children are active cognising agents who learn through interacting with the world and each other. At first glance, it is difficult to appreciate how this approach can underpin online pedagogy in the complete absence of any face to face teaching. And this is the point I need to stress; while there is a large body of research indicating the positive outcomes of using technology as a tool in a traditional lesson, we are now faced with a situation where there is no face to face engagement possible. This is especially challenging in a developing context such as South Africa where around 70 per cent of the population has limited or no access to connectivity prohibiting the use of software that permits face to face engagement, such as Zoom. While, there is a body of evidence from the literature illustrating how effective teaching with technology, especially mobile technology, can be in a traditional lesson as an addition to the face to face instruction, there is very little literature indicating how pedagogy with technology can be developmental outside of the traditional classroom (Papadakis, Kalogiannakis, and Zaranis 2016; Tay 2016; Dalby and Swan 2019; Goos 2020; Fisher et al. 2013; Tay 2016; Geer et al. 2017). In the absence of any recourse to face to face pedagogy, how can online pedagogy develop students cognitively? This is the question that the article seeks to address by drawing on the work of Vygotsky and Hedegaard to argue for how digital pedagogy can indeed be developmental. The article, therefore, presents exploratory research and concerns itself with answering the following question:

- How can one teach through technology in the absence of face to face pedagogy?

I begin, first, with a cultural historical understanding of what exactly teaching is.

\section{A CULTURAL-HISTORICAL APPROACH TO PEDAGOGY: OBUCHENIE}

"The Russian word obuchenie does not admit to a direct English translation. It means both 
teaching and learning, both sides of the two-way process, and is therefore well suited to a dialectical view of a phenomenon made up of mutually interpenetrating opposites" (Sutton 1980, 169-170, in Mahn 2013).

The quote above is based on dialectical rather than binary logic that sees the process of pedagogy as one of teaching/learning where both are inextricably intertwined with each other. This view of pedagogy stems from Vygotsky's $(1978 ; 1986 ; 1987)$ work around cognitive development. For Vygotsky, for development to occur a student needs the assistance of a culturally more capable other, or teacher to guide them beyond what they are currently capable of doing independently. The notion of interpersonal interaction becoming intrapersonal through mediation across time is outlined in Vygotsky's General Genetic Law where he states that what begins first as a relationship (generally in dialogue) between the student and the teacher (or care giver and child) becomes internalised over time as the student's own thinking. Mediation, moreover, happens in a unique social space that opens up in interaction: the Zone of Proximal Development (ZPD). The ZPD is unique to each child and represents the difference between what the child can achieve independently and what they can achieve through mediated interaction. For Vygotsky, (1978; 1987, 113),

\begin{abstract}
"The zone of proximal development defines those functions that have not yet matured but are in the process of maturation, functions that will mature tomorrow but are currently in an embryonic state. These functions could be termed the 'buds' or 'flowers' of development rather than the 'fruits' of development. The actual developmental level characterizes mental development retrospectively, while the zone of proximal development characterizes mental development prospectively."
\end{abstract}

As we can see from the above quote, the buds of development lie in the ZPD, ready to be grown through assistance. Through the process of mediation, these buds are developed into higher cognitive functions over time. It is important to note that mediation is not synonymous with the Western notion of scaffolding coined by Wood, Bruner, and Ross (1976), although many writers (see for example Wink and Putney 2002) tend to elide the two terms. Unlike mediation, which is specifically geared towards the development of higher cognitive functions over time, scaffolding is task specific. One could use scaffolding techniques in order to mediate, however, scaffolding cannot be thought of as the process of mediation. It is within this zone that the development of abstract concepts can happen.

Vygotsky (1986) distinguishes between spontaneous, everyday concepts and scientific or abstract concepts. Whereas spontaneous concepts are acquired through empirical experience, scientific concepts must necessarily be taught by a more culturally competent other. Scientific concepts, then, are the kinds of concepts taught in schools (Hedegaard 1998). However, 
spontaneous and scientific concepts are dialectically entailed; without reference to spontaneous concepts scientific concepts cannot be meaningfully appropriated and similarly, spontaneous concepts cannot reach consciousness without being linked to scientific concepts. Scientific concepts develop over time and it is for this reason that the ZPD needs to be seen as distinct from scaffolding (Wood et al. 1976). While scaffolding is task and activity specific, mediation takes place in the ZPD over a long period of time and is not linked to any set task or activity, but is a developmental zone that leads, eventually, to the child developing higher cognitive functions (Karpov 2005). I argue that the unique communicative space of the ZPD makes it a dialogical rather than monological space. My argument for dialogicality rests on the fact that meanings are co-constructed in the ZPD, between the teacher and the taught. Both participants move towards negotiating the meaning of the concept taught and both therefore, learn. It is in this sense, an almost Freirian (1970) sense, that I conceive of the ZPD as dialogical. For Freire (1970), the "word" gains meaning only in praxis; there is no learning when the word is merely presented - it is just verbalism. However, in praxis, between two interlocutors who negotiate meaning, the word gains meaning. It is in much the same way that the scientific concept is devoid of meaning in the absence of the spontaneous concept. The dialectical logic underpinning Vygotsky's work overcomes the binary logic favoured in the West through overcoming false binaries such as mind/society and constituting these as dialectical relationships, mind in society. The everyday concept gives meaning to the abstract concept while the abstraction moves the everyday into consciousness allowing for reflection. It is important to note that this process requires movement from both the teacher and the taught: that is, meaning is negotiated in the ZPD between teacher and taught. This requires a dialogical engagement where partners move towards a shared meaning of the concepts under discussion. This is not unlike Charles Taylor's (1991) notion of horizons of significance, where a task becomes authentic and meaningful through dialogue. While Vygotsky's (1978; 1986) work outlines the dialectical link between scientific and spontaneous concepts, he does not fully illustrate how one can operationalise this in relation to studying learning/teaching in classrooms. It is here that Hedegaard's (1998) work in radical local pedagogy provides a basis for understanding how these concepts can be linked to develop children cognitively in a classroom.

\section{THE DOUBLE-MOVE IN PEDAGOGY}

Chaiklin and Hedegaard (2013) propose a novel developmental pedagogy that they call a radical local model of pedagogy. What is of interest in this model is their recruitment of students' cultural repertoires to access and understand scientific (school) concepts. Drawing on Freire 
(1970) as well as Davydov (1988), they illustrate through this model that school knowledge should not be decontextualized but should be able to alter the students' lived experience in real life, authentic situations. The crux of this model is located in the double-move in pedagogy in schools, where theoretical knowledge (from abstract concepts) is linked to empirical knowledge (derived from spontaneous concepts) (Hedegaard 1998). For Hedegaard, knowledge ascends from the abstract to the concrete, with abstraction only being understood and internalised in relation to everyday, spontaneous concepts. Failure to link the scientific concepts with the everyday concepts will lead to either a lack of understanding, a mere hollow verbalism of the scientific concept or to merely empirical knowledge of the problem under study. Pedagogy using the double-move requires that "... the teacher guides the learning activity both from the perspective of general concepts and from the perspective of engaging students in 'situated' problems that are meaningful in relation to their developmental stage and life situations" (Hedegaard 1998, 120). It is in Hedegaard's (1998) work that we find a mechanism for operationalising Vygotskian dialectical logic through the double-move in pedagogy. In what follows I draw on ongoing research to illustrate how this can be achieved.

\section{METHODOLOGY}

\section{Research design and methods}

As this work is located in a cultural historical framework, it lends itself to a qualitative methodology. A single case-study design was adopted as the research is exploratory in nature and seeks to understand how a pedagogical model might work online (Yin 1981). Data, in the form of student responses to questions posed online, were collected online. The online environment was designed by the researcher following the pedagogical principals outlined above in the article. The UCT's online learning portal, vula, served as the site for students to access the texts they are required to interrogate and the concepts they are required to acquire.

\section{Sample, participants and context}

Given the exploratory nature of this research, a purposive sample was chosen. The criteria for choosing the sample were 1) students must be registered for my honours course, 2) students must be in-service teachers, and 3) students must be willing to participate in the research. Thirsty honours students participated in this research. All are in-service teachers ranging in age from 24 to 52 years. The average age of participants was 34. Seventeen women and 13 men took part in the research. All names have been altered to ensure confidentiality.

Participants are students registered for a course on Vygotskian notions of 
teaching/learning in the School of Education, at the University of Cape Town, which runs for 5 weeks for $2.30 \mathrm{hrs}$ per week. An online portal for the course was set up using vula. Due to COVID and the subsequent lockdown, no face to face teaching happened on this course. The site was set up, therefore, based on the principles described in the beginning of this article. A week before the start of the course students were required to access a quote online and to generate questions in relation to this quote: this was recorded as Task 1.

Task 1: Read the following quote and ask any questions that will help you to understand it better. We will address this in our first lecture.

"It is not the consciousness of men that determines their being but, on the contrary, their social being that determines their consciousness." (Marx 1970, 328-329).

Participants were then required to generate questions in response to this quote. That is, the quote was given in order to probe their understanding of cultural historical work. The posed questions, therefore, provide insight into participants ZPDs by showing what they know in relation to the quote and what they still need to learn in order to fully grasp the conceptual basis of the quote.

On the first day of lectures, a forum was set up where participants were asked to give their own personal understanding of how someone learns and therefore, how one should teach; this was recorded online as Task 2. This forum, then, was aimed at eliciting participants' everyday understandings of teaching/learning before introducing them to the scientific concepts of teaching/learning drawn from Vygotsky and Neo-Vygotskians.

Task 2: Before you read any of the course material, in your own words, describe how you think a person learns and therefore, how one should teach.

All lectures were online and no face to face teaching happened. Zoom was not feasible with such a large group and therefore, lecture ppt slides were given to the students to read together with an audio recording of the slides. In the third week of lectures, participants were presented with the following scientific concepts to define pedagogy:

Task 3: Drawing on what we have discussed so far in the course, explain this quote in your OWN words.

"A structured process whereby a culturally more experienced peer or teacher uses cultural tools to mediate or guide a novice into established, relatively stable ways of knowing and being within a particular, institutional context, in such a way that the knowledge and skills the novice acquires lead to relatively lasting changes in the novice's behaviour; that is, learning." (Hardman 2007, 5).

This was recorded as Task 3. Weeks 4 and 5 of the lecture series were used to elaborate on this 
definition and to link it to the everyday, spontaneous concepts participants had produced in the week prior to module commencement.

\section{FINDINGS AND DISCUSSION}

\section{Ascertaining the ZPD through technology}

Task 1 required that students interrogate a quote by Marx that illustrates and indeed, underpins Vygotsky's general genetic law of development: viz. that a person becomes conscious of who they are only through interaction with others. Actual social relations begin as dialogue between interlocutors before being internalised as part of a person's unique cognitive make-up. In the absence of having read Marx or Vygotsky, this quote is rather opaque and I hoped it would give me access to the participants' ZPD by showing me what they do not know and therefore, what I will need to teach them, through mediation. Extract 1 below contains some of the common types of questions asked

\section{Extract 1: Task 1: Accessing the ZPD \\ Suzy: "How would one define consciousness?" \\ Andile: "Does this mean that the social context determines how you think?" \\ Nongazi: "What does it mean by 'determines'?"}

Most students were unsure what consciousness referred to and struggled with understanding how social relationships become internalised as the self. There was, therefore, a gap in the participants ZPD that I addressed in my first lecture through a detailed discussion of the general genetic law. The use, therefore, of a quote to spark questioning from participants even in the absence of face to face interaction proved to be capable of illustrating the different ZPD's in the classroom.

\section{Extract 2: Task 2: Everyday concepts - How do you think people learn?}

Sara: "Children learn best in an environment where they feel free to take risks. They learn from others by being appropriately 'scaffolded' from the 'known to the unknown'. They learn through questioning and through play."

Bongani: "Moving from something concrete into abstract. Influential people in their lives, family, friends, teachers, etc. Media, advertising (subliminal). Also by doing it, by the practical activity."

Akhona: $\quad$ "They should be context - i.e., how does this relate to me in my world and how can I apply it in situations that I am face with. Through learning they should be given opportunity to practice the now learning in authentic situations. After applying the new skill/ knowledge, they should relate it on what has changed in their lives and how they can implement it going 
forward. This should be a person reflection."

Mashudu: "Students at vocational colleges learn by doing. Lots of my student fare well in practical subject and grapple with contents subjects. I have also found that my students are visual learners. It is important when I prepare my lesson that I consider the different leaning styles. So you will see posters, word walls, Power Point presentations and some degrees of videos. A typical lesson for me starts with a new topic + or -10 mins, +/- 30 mins students are engaged practically and $+/-10$ mins to wrap up the session."

Sam: "Children learn by discovering things on their own. They fiddle around, try out things and figure out how things work which is learning."

Refilwe: "I thinks children learn by internalising, i.e. whatever they are taught if not practical then chances are that they won't learn and thus forget. So children will learn things that are taught to them form either teachers observing and doing and from peers and family by doing."

Extract 2 contains representation of the types of responses received from students. 28 of 30 students believed that people learn through experience, or "by doing". That is, a prevalent everyday concept that participants mobilise to explain how learning happens is "experience". Since at least the middle of the $20^{\text {th }}$ century the notion that learning is an active, rather than passive endeavour has been entrenched thanks in large part of Piaget's (1976) genetic epistemology that conceives of children as active cognising agents. However, this understanding of learning is based in the empirical realm; that is, what can be learnt from experience is different to what is learnt in institutions such as schools. So, this understanding of learning is only part of the picture of how learning, as relates to cognitive development, actually happens. Experiential knowledge is empirical knowledge and can often lead to misunderstandings. Take for example, a dolphin and a tuna fish. They both have fins and live in the sea. They must, therefore, be the same species. Of course, though, the essential attributes of a dolphin (air breathing and giving birth to lives young) have more in common with say a cow, than a tuna fish. Left only at empirical observations, a person would have no way of learning about the mammalian kingdom and the specific concepts contained within it. The concepts utilised in school and university, are abstract scientific concepts that must necessarily be taught and cannot be learnt merely through experience. However, given South Africa's recent history of Outcomes Based Education, which leaned heavily on the notion of experiential learning and teaching, it is not surprising that these participants, who are all teachers, should hold this rather common sensical notion of how learning happens. However, in the absence of structured assistance, a student cannot learn abstract concepts on their own. They need to be guided into these culturally accepted ways of knowing by a more competent other. To achieve a deeper understanding of learning as development, this everyday understanding of learning can be harnessed and linked to the scientific understanding of learning as an active process. This notion of learning as requiring active cognising agents was taken up and linked to the notion of mediation in the forum that followed this task, thereby linking the everyday with the 
scientific.

None of the participants pointed to the notion of mediation as core to teaching/learning. This was however, not expected as students had not yet engaged in the module. The challenge I now faced was to link the everyday knowledge of the participants with the scientific concepts about teaching/learning they were required to acquire in the module in such a manner that 1) misunderstandings were not perpetuated and 2) that the abstract concept of mediation could be linked to their everyday knowledge of learning/teaching, thereby deepening and altering that knowledge. In task 3, the abstract definition of pedagogy was presented to participants. This was followed up with an online forum where participants' everyday notions of learning as active, could be linked with the notion of mediation, an essentially active process of dialoguing through the ZPD.

\section{Extract 3: Linking the everyday and the scientific in the double-move}

Drawing on what we have discussed so far in the course, explain this quote in your OWN words.

"A structured process whereby a culturally more experienced peer or teacher uses cultural tools to mediate or guide a novice into established, relatively stable ways of knowing and being within a particular, institutional context, in such a way that the knowledge and skills the novice acquires lead to relatively lasting changes in the novice's behaviour; that is, learning." (Hardman 2007, 5).

Conceptual explanation:

Mediation: A process of structured guidance where someone who is culturally more experienced assists and guides the novice in problem solving.

Institutional context: Referring to school or institution in which a body of knowledge is being acquired.

Learning: When new knowledge is acquired that changes the way a person approaches the world.

\section{Extract 4: Definition of pedagogy: Participants' own words}

Maya: "So what it means for me is that a teacher or someone who knows more than the student must give guidance to the student to help them to obtain different or new learning. This would be in an activity so they would be learning through engaging in something. For me this means the teacher is central in developing knowledge."

Lihle: $\quad$ "A teacher is essential is providing structure for the student to acquire new knowledge. This new knowledge we call learning. It is different to the knowledge they learn on their own because it happens in an institution."

What we can see in extract 4 is that students are able to harness the scientific concepts and relate these to their everyday understandings of learning/teaching as an active process; however, their understanding of teaching/learning has altered now to include the scientific notion of mediation into their explication of learning. Of particular interest is the move from children being able to learn on their own (empirical knowledge) to an understanding that a teacher is 
central to developmental learning. We may hypothesise that this new information will alter their pedagogical practices in actual classrooms.

Finally, in order to ascertain if students had acquired the scientific concepts in this course, I set them a 3000-word essay. The following question was posed:

"The Meno paradox states: A man cannot inquire either about that which he knows, or about that which he does not know, for assuming he knows he has no need to inquire, nor can he inquire about that which he does not know, for he does not know about that which he has to inquire." (Fine 1992, 221).

Using the concepts you have learnt in this course, indicate how you would solve this paradox.

This high-level question requires that students can mobilise both their everyday understanding of learning as an active process as well as the scientific concepts taught in the course, such as mediation in the ZPD. Essay marks were taken as indicators of participants' success at linking these concepts and developing a sense of the material presented in the course through, rather than merely with technology. Fifteen percent of the class obtained $1^{\text {st }}$ class passes between $75-$ 89 per cent. An indication of a first-class response is, in part, given below.

Sia:

"So, I can conclude, that the meno paradox can be overcome by recognising that a person must actively engage with a more knowledgeable other in order to gain, or in fact, grow, new knowledge. The process underpinning this is termed mediation, a form of guidance that links abstract knowledge with what the student already knows, that is, everyday knowledge."

Twenty-seven per cent of the class obtained between 70-74 per cent on this essay; 38 per cent passed with a mark between 60-69 per cent and 20 per cent obtained a mark between 50-59. No-one in the class failed the essay. While these essay marks are satisfying, I am not in a position to attribute this entirely to the online learning given in the course, or indeed to the pedagogical model used as this is an exploratory case study, not a quasi-experimental design. At best, I can suggest that the cultural historical model developed in this article as a pedagogical model capable of enabling teaching online through rather than merely with technology, is promising. More research is clearly required in this area and a quasi-experimental design would be one way to ascertain if it is the online pedagogical model that underpins students' success in this course. This was not the purpose of this article; I set out in this article to explore in what ways a cultural historical model of pedagogy, drawing on Vygotsky and Hedegaard, could facilitate students' access to academic knowledge in the absence of face to face teaching. The results reported above are indicative of the models' capacity to 1) ascertain a zone of proximal development through online questioning, 2) to elicit students' everyday knowledge and 3) to introduce scientific concepts and link them to students' everyday concepts in meaningful ways. 


\section{CONCLUSION}

In the increasingly challenging world provided by the COVID-19 pandemic, academics and teachers are being forced to work online in ways never seen before. While teachers and academics have traditionally used technology as a tool to teach with, during the pandemic, technology has often had to replace the teacher due to limited band width and data constraints, which make zoom lessons inaccessible for many. This article outlines a cultural historical pedagogical model for teaching through technology in the absence of any face to face interaction from a teacher or academic. The exploratory article sets out how one can weave this pedagogical model into an online environment. I make no claims about generalizability of this study; this is a small case study design and could only be replicated with students in similar contexts. However, data from the students' interaction online is suggestive of students acquiring the scientific concepts taught in this course, even in the absence of a lecturer in a face to face modality. Further research that adopts a quasi- experimental design is advised.

\section{REFERENCES}

Dalby, D. and M. Swan. 2019. "Using digital technology to enhance formative assessment in mathematics classrooms." BJET 50: 832-845.

Davydov, V. V. 1988. "Problems of Developmental teaching: The experience of theoretical and experimental psychological research excerpts (part 1)." Soviet Education 30(8): 94.

Falloon, G. and E. Khoo. 2014. "Exploring young students' talk in iPad-supported collaborative learning environments." Computers \& Education 77: 13-28.

Fine, G. 1992. "Inquiry in the Meno.” In The Cambridge companion to Plato, ed. R. Kraut, 200-226. Cambridge University Press.

Fisher, B., T. Lucas, and A. Galstyan. 2013. "The Role of iPads in Constructing Collaborative Learning Spaces." Technology, Knowledge and Learning 18(3): 165-178.

Freire, P. and M. B. Ramos. 1970. Pedagogy of the oppressed. New York: Continuum.

Geer, R., B. White, Y. Zeegers, W. Au, and A. Barnes. 2017. "Emerging pedagogies for the use of iPads in schools." BJET 48: 490-498.

Goos, S. 2020. "1:1 iPads and Student Achievement." Thesis, Concordia University, St. Paul. https://digitalcommons.csp.edu/teacher-education_masters/20.

Hardman, J. 2007. "Towards a methodology for using Activity Theory to explicate the pedagogical object in a primary school mathematics classroom." Critical Social Studies (1): 53-69.

Hardman, J. 2020. "Into the abyss: Online teaching/learning in a pandemic." Mail and Guardian 4 May: 31. Cape Town May.

Hedegaard, M. 1998. "Situated learning and cognition: Theoretical learning and cognition." Mind, Culture and Activity 5(2): 114-126.

Karpov, Y. V. 2005. The Neo-Vygotskian Approach to Child Development. Cambridge University Press. https://doi.org/10.1017/CBO9781316036532.

Marx, K. 1970. A contribution to the critique of political economy. Moscow: Progress Publishers.

Mercer, N., L. Dawes, and Kleine J. Staarman. 2009. "Dialogic teaching in the primary science 
classroom." Language and Education 23(4): 353-369. DOI: 10.1080/09500780902954273.

Papadakis, S., M. Kalogiannakis, and N. Zaranis. 2016. "Developing fundamental programming concepts and computational thinking with ScratchJr in preschool education: A case study." International Journal Mobile Learning and Organisation 10(3).

Piaget, J. 1976. To understand is to invent. Harmondsworth: Penguin.

Rosen, Y. and G. Salomon. 2007. "The Differential Learning Achievements of Constructivist Technology-Intensive Learning Environments as Compared with Traditional Ones: A MetaAnalysis." Journal of Educational Computing Research 36(1): 1-14.

Roschelle, J., K. Rafanan, R. Bhanot, G. Estrella, B. Penuel, and M. Nussbaum. 2010. "Scaffolding group explanation and feedback with handheld technology: Impact on students' mathematics learning." Educational Technology Research and Development 58: 399-419. 10.1007/s11423009-9142-9.

Sutton, A. 1980. "Backward children in the USSR." In Home, school and leisure in the Soviet Union, ed. J. Brine, M. Perrie, and Andrew Sutton, 160-191. St. Leonards, Australia: Allen \& Unwin.

Tamim, R. M., R. M. Bernard, E. Borokhovski, P. C. Abrami, and R. F. Schmid. 2011. "What Forty Years of Research Says About the Impact of Technology on Learning: A Second-Order MetaAnalysis and Validation Study." Review of Educational Research 81(1): 4-28.

Tay, H. Y. 2016. "Longitudinal study on impact of iPad use on teaching and learning." Cogent Education 3: 1. DOI: 10.1080/2331186X.2015.1127308.

Taylor, C. 1991. The Ethics of Authenticity. Cambridge, Mass.: Harvard University Press.

Vygotsky, L. S. 1978. Mind in society. The development of higher psychological processes. Translated and edited by M. Cole, V. John-Steiner, S. Scribner, and E. Souberman. Cambridge, MA: Harvard University Press.

Vygotsky, L. S. 1986. Thought and language. Translated and edited by E. Hanfmann and G. Vakar. Cambridge, MA: MIT Press.

Vygotsky, L. S. 1987. The collected works of L. S. Vygotsky, Vol 1: Problems of general psychology, ed. R. W. Rieber and A. S. Carton. Translated by N. Minick. New York: Plenum Press.

Wink, J. and L. Putney. 2002. A Vision of Vygotsky, 102-112. Boston, MA: Allyn \& Bacon.

Wood, D., J. S. Bruner, and G. Ross. 1976. "The role of tutoring in problem solving.” Journal of Child Psychology and Psychiatry 17: 89-100.

Yin, R. K. 1981. "The Case Study as a Serious Research Strategy.” Knowledge 3(1): 97-114. doi: 10.1177/107554708100300106.

Zurita, G. and M. Nussbaum. 2004. "Computer supported collaborative learning using wirelessly interconnected mobile computers." Computers \& Education 42(3): 289-314. DOI: 10.1016/ j.compedu.2003.08.005. 